\title{
EXENTOS II. EXAMEN DE DOS PASIONES: LA MIRADA Y LA REESCRITURA
}

\section{José Enrique MARTÍNEZ}

Universidad de León

anto en Edad (1987) como en Esta luz (2004) aparece, como sección V en la primera
recopilación y como tal, pero sin numerar, en la segunda, un conjunto de poemas titulados
Exentos II. Pasión de la mirada, con las fechas de composición 1963-1970, a las que se añade «y 2003» en Esta luz debido a la revisión o reescritura sufrida por dos de las composiciones. Orgánicamente, Pasión de la mirada se sitúa entre Blues castellano y Descripción de la mentira y consta de 24 composiciones. El número romano II de Exentos se debe a la existencia de Exentos I (1959-1960 y 2003), con 9 piezas, entre Sublevación inmóvil y Blues castellano, y de Exentos III (19902003 y 2004), con cinco piezas, entre Cecilia y Mudanzas.

«Exentos», de «eximir», indica que algo está libre, es decir no sometido a una jurisdicción o autoridad del tipo que sea; en el conjunto de la poesía de Gamoneda, la palabra indica que los poemas exentos no están sometidos al gobierno o la ley de un poemario previo. Así sucede en el caso de Exentos II, con la excepción de cinco composiciones que pertenecieron originariamente al libro León de la mirada publicado en 1979 y reescritos al pasar a la sección V de Edad.

El título León de la mirada inspiró el de Pasión de la mirada, reflejo fónico del primero y, en parte, también semántico. El título segundo suponía ya una reescritura y, con ella, la incardinación de los cinco poemas rescatados del contexto original en la fluencia general del río poético gamonediano; pero como en toda reescritura, el avance se produce sin olvidar el punto de partida; la concreción limitadora del topónimo, «León», se abre a un significado más vasto, «pasión», sin que nos oculte su procedencia. «Pasión» tiene en el uso dos acepciones principales y diferentes: por un lado colinde con «padecer»; por el otro, alude a un deseo vehemente de algo; en el primer caso el sujeto es un ser pasivo, como el Prometeo de Sublevación inmóvil; en el segundo es el sujeto quien activa su fervor: es esta segunda, naturalmente, la acepción de la palabra en Pasión de la mirada. La «mirada» es ese algo por el que el sujeto -el poeta diré en adelante- siente pasión. Si en León de la mirada, esta se cernía sobre una geografía concreta, con nombre propio («De esta mirada surgirá mi canto», decía en el poema inicial, aludiendo a «tierra León, amiga y madre mía»), la mirada de Pasión pretende ser generalizadora y abarcar una actitud característica del poeta a lo largo de su obra. «Ver»y «mirar» son, en efecto, 
signos de esa actitud reiterados libro tras libro, si bien en algunos tienen una presencia ciertamente relevante. Recorriendo la obra del poeta puede atestiguarse la presencia explícita de estas formas verbales en primera persona y extraer algunas mínimas conclusiones: existe una triple perspectiva, una mirada interior, hacia uno mismo, una mirada hacia lo que nos rodea y la mirada visionaria que percibe un mundo irreal. La mirada subjetiva va de la conciencia al mundo; la objetiva, del mundo hacia la conciencia; la visionaria es esencialmente creadora. La mirada subjetiva, la que se dirige hacia el interior de uno mismo, se exterioriza con la palabra; en la objetiva aparece un yo testigo que testimonia lo que ve y lo que mira; la visión concibe mundos irreales imaginarios. La mirada subjetiva supone un mirar metafórico, un mirar con los ojos del alma, por así decir; la mirada hacia el mundo responde a una realidad, la que los ojos reales del cuerpo vieron o ven; la visión es propia de la imaginación o de la fantasía. Cabe suponer que las distintas perspectivas se conjugan y confunden en determinadas composiciones. En los Primeros poemas, titulados La tierra y los labios, así como en Sublevación inmóvil, abunda la mirada interior y metafórica, como observamos en un único ejemplo: el soneto que cierra La tierra y los labios testimonia la pérdida dolorosa de la fe, en un proceso que ha dejado al sujeto cruelmente desposeído; el soneto pertenece semánticamente al ámbito prometeico, el del dioshombre atormentado y despojado; arrancado Dios violentamente del alma, el poeta o sujeto busca vestigios del fuego que lo habitó: «Ahora miro en mí por si han dejado / aunque no sea más que unos despojos»; es la mirada interior que percibe como único resto el vacío ${ }^{1}$. A partir de Blues castellano es la mirada sobre el mundo la que predomina, un mundo que el poeta interioriza para devolvérnoslo como representación estética. En ese libro, determinados poemas expresan la solidaridad, el amor, la comprensión a través del rostro que uno mira, el rostro de la madre: «Yo sé que en cada rostro se ve el mundo», escribe el poeta en «Hablo con mi madre». Pero es en la sección tercera de Lápidas donde se multiplican los signos explícitos del yo testigo al reconstruir desde la memoria personal un pasado colectivo, el de la guerra civil vista con los ojos del niño que desde los hierros del balcón contempla cadenas de presos, trenes de los que descienden hombres cenceños con el dolor en el rostro: ver y mirar remiten a ese pasado vivo en el recuerdo, autobiográfico hasta el punto de que de los poemas son aprovechados por Andrés Sorel en Iluminaciones ${ }^{2}$ para trazar la biografía gamonediana y la radiografía de una ciudad en guerra. La «pasión por la mirada» se acentúa en Arden las pérdidas, donde la reiteración de «vi» $\mathrm{y}$ «veo» marca el contraste entre el pasado más o menos luminoso y un presente de vejez abocado al blanco de la muerte, con fórmulas como «Vi... / Ahora ya no veo...» ${ }^{3}$ «Yo vi... / Ya sólo veo...» ${ }^{4}$, «vi la muerte... / Ahora mis ojos ven...» ${ }^{5}$. Desde la «claridad sin descanso» de la vejez, el poeta evoca un pasado que percute en el presente; es una «memoria despedazada» la que activa el recuerdo, porque lo que arde en la memoria son pérdidas y desapariciones, mientras se siente la amenaza de la luz blanca.

\footnotetext{
${ }^{1}$ A. Gamoneda (2004), Esta luz, 37.

${ }^{2}$ A. Sorel (2008), Iluminaciones.

${ }^{3}$ A. Gamoneda, Esta luz, op. cit, 421.

${ }^{4}$ Ibid., 453.

${ }^{5}$ Ibid., 454.
} 
Curiosamente los signos verbales en primera persona, alusivos a la acción de mirar, son escasos en Pasión de la mirada. Solo los hallamos en dos composiciones: en «Recuerdo que la tierra quiebra dura», donde la memoria activa el paisaje contemplado («Vi / ásperos pueblos, huertos silenciosos»), como correlato del corazón del hombre: «Miré también al corazón humano / y vi la misma lentitud» ${ }^{6}$; también en el poema «Dios extendido, longitud sagrada» se reiteran dichas formas verbales al describir la figura escultórica del crucificado: «Veo la boca... / miro los brazos...» ${ }^{7}$. Sin embargo, todo el poemario deriva de una misma actitud de contemplación y creación: contemplación sucesivamente del corazón, del paisaje y del arte, y creación correlativa de tres espacios poéticos intercomunicados como sagazmente dedujo Miguel $\mathrm{Casado}^{8}$, que habló también de «espacio irreal y simbólico» para el conjunto, sin que obviemos el hecho de que la realidad originaria que subyace se nos va entregando más y más en cada relectura, con cada fisura que vamos abriendo en la opacidad de los textos. «Astillas, soledad, tierras, estatuas»: este verso con que termina el primer poema reclama los tres espacios de la mirada ya indicados, el interior de la soledad, el externo de la naturaleza y el del arte, mientras que «astillas» alude a los restos o vestigios de «las adánicas, redondas / palabras oferentes» que el poeta busca desde la carencia («vivo sin padre y sin especie; callo» ${ }^{9}$ ).

El ámbito interior, el de la soledad, el del corazón, es un espacio metafórico, «landa que no es lugar, sino dolor» ${ }^{10}$, llanto y pensamientos de muerte. En la transitividad entre los espacios de la que habló Casado ${ }^{11}$, la «selva roja donde el agua nunca / la luz destella», ni hay pájaros que de la espesura eleven su canto en el azul no es una naturaleza complaciente, sino que va sumando signos negativos para escuchar únicamente al corazón «latir en soledad, pero llorando» ${ }^{12}$; así termina el tercer fragmento de Pasión de la mirada, y de igual modo, el fragmento cuarto, considerablemente oscuro, concluye aludiendo al bosque que «abre sus frutos y los manantiales / manan lentos en mí. Pero llorando». Son términos que, al redundar, dan continuidad, transitividad, a los diferentes fragmentos y convocan una misma tonalidad sentimental en la que inciden imágenes de otras composiciones, como «la paloma del llanto» o «la piel del dolor ${ }^{13}$, por ejemplo. Desde mi punto de vista, el corazón es el verdadero sujeto semántico de este espacio interior, sinécdoque que concentra los sentimientos y pensamientos de dolor, soledad y muerte.

El espacio natural procede, aunque no exclusivamente, de los poemas extraídos de León de la mirada. El poeta contempla y canta. Puede contemplar una naturaleza benigna, como en el fragmento que comienza «Está tejida con azul la noche»: en el silencio crepuscular alienta el deseo de penetrar en la vida de las cosas y en la verdad de uno mismo: «salgo a los huertos / y me busco en las aguas y las sombras» ${ }^{14}$; en «Recuerdo que la tierra quiebra dura», la tierra hendida, las rocas, los ríos originales

\footnotetext{
${ }^{6}$ Ibid., 154.

${ }^{7}$ Ibid., 163.

${ }^{8}$ M. Casado (1987), «Introducción», A. Gamoneda, Edad, 27.

${ }^{9}$ A. Gamoneda, Esta luz, op. cit, 145.

${ }^{10}$ Ibid., 146.

${ }^{11}$ M. Casado, «Introducción», Edad, op. cit, 27.

${ }^{12}$ A. Gamoneda, Esta luz, op. cit, 209.

${ }^{13}$ Ibid., 151.

${ }^{14}$ Ibid., 153.
} 
y otros elementos naturales sirven de correlato a la naturaleza interior del corazón ${ }^{15}$; en general el campo es el espacio de la serenidad; también de la belleza espontánea, no creada por el hombre; en el poema «La tarde entra de pronto en la cocina», por ejemplo, se respira la apacibilidad crepuscular en la luz que inunda la casa y los objetos y los rostros, en un silencio que preludia el más compacto de la noche. En la poesía de Gamoneda hay constancia de la belleza contemplada; pero no es una belleza pasiva, ni está inmóvil en las cosas, ni tiene sentido si no va unida al hombre, a la justicia o a la libertad. Se canta la belleza desde una actitud ética.

El ámbito del arte, estatuario y arquitectónico configura el tercero de los espacios. Volúmenes, materia, formas: columnas, capiteles, estatuas, vidrieras. No un arte frío, sino expresivo. Se canta desde los sentimientos que produce en un sujeto receptivo. En las cabezas del capitel «se averiguan / sólo la dimensión y la tristeza» ${ }^{16}$; en la madera de las estatuas «el oro canta. Y el dolor» ${ }^{17}$; también llega de sus formas un sentimiento amable: «la física dulzura / que entra despacio al corazón y habla» ${ }^{18}$. Los poemas respiran continuidad, de las «cabezas congregadas» del capitel a las estatuas humanizadas que «invocan la vejez» o expresan dolor o dulzura. «La que habla en volumen, la que mide / el destino con sola su existencia» ${ }^{19}$ es probablemente la estatua de Cristo que, en otro poema, se concreta en la figura yacente de Gregorio Fernández que el poeta contempla en sus detalles: «Veo la boca / donde pastan la luz y las tinieblas; / miro los brazos de marfil y espino» ${ }^{20} ;$ ¿y no es a la estatua de un Cristo azotado «las duras manos torturando columnas» y cuyos «huesos sienten la sustancia mortal»-a la que se alude en el poema «Aquí la boca, su oquedad eterna», cuyo silencio es más expresivo que la palabra? «Obstinada belleza ${ }^{21}$ en el dolor, aparente contradicción que ha tratado de resolver el poeta: «La poesía [digamos nosotros el arte en general] existe porque sabemos que vamos a morir [...]. Pues bien, la poesía implica placer en este conocimiento» ha escrito Gamoneda ${ }^{22}$. La relación interartística que suponen estos poemas se intensifica en el más extenso de Pasión de la mirada, el que comienza: «Un bosque inmóvil, sin espacio», poema majestuoso, asombro ante «la arbolada vidriería» de un templo, asombro vertido en abundancia de palabras y en oxímorons como «llano vertical», «callada tempestad», «canta pero extiende silencio», etc., que dan cuenta de una écfrasis compleja y difícil, con todos los problemas que, además, supone la naturaleza del poema ecfrástico, representación de una representación.

Los tres espacios construidos («Espacio siempre frente al tiempo», dice uno de los poemas ${ }^{23}$ ) proporcionan cierta unidad a la serie de Pasión de la mirada, «seguramente estructurada en torno al tema que le da título, a la contemplación», como ha escrito Casado ${ }^{24}$, sea una mirada al corazón, al

\footnotetext{
15 Ibid., 154.

${ }^{16}$ Ibid., 158.

${ }^{17}$ Ibid., 160.

${ }^{18}$ Ibid., 161.

${ }^{19}$ Ibid., 162.

${ }^{20}$ Ibid., 163.

${ }^{21}$ Ibid., 168.

${ }^{22}$ A. Gamoneda (1997), «Poesía y conocimiento. ¿Qué conocimiento?», El cuerpo de los símbolos, 34.

${ }^{23}$ A. Gamoneda, Esta luz, op. cit, 169.

${ }^{24}$ M. Casado, «Introducción», Edad, op. cit, 27.
} 
paisaje o al arte, lo que el crítico citado relaciona en cada caso con libros anteriores del poeta, incardinando de este modo los poemas de Exentos II en la fluencia de la obra tal como se organizó en Edad primero y en Esta luz después. Existe además una unidad formal, rítmica, métrica, pues el conjunto es, en Esta luz, una sucesión de 306 endecasílabos blancos distribuidos en 24 fragmentos o poemas; añadamos la unidad de tono sentimental que proporcionan la unión de belleza y dolor, como ya hemos sugerido.

La otra pasión a la que me quería referir brevemente es la de la reescritura. En 2004 publicó Gamoneda Reescritura ${ }^{25}$, una serie de poemas sometidos a tal proceso, con un preámbulo que, en parte, reincorporó a Esta luz, y en el que plantea la cuestión, tan debatida en casos como el de Juan Ramón Jiménez, de si los poemas reescritos son o no poemas diferentes de los originarios, pues de ellos han dependido en su confección y de ellos permanecen huellas reconocibles que permiten entender la reescritura como escritura palimsésptica. La cuestión es muy interesante en el caso de los poemas extraídos de León de la mirada y reincorporados a Pasión de la mirada. Sobre ese proceso escribí algunas páginas en mi libro La intertextualidad literaria ${ }^{26}$. En rápido resumen puede decirse: a) de los veintinueve poemas de León de la mirada, Gamoneda rescató para Pasión únicamente cinco; b) en la reescritura de los cinco poemas el poeta «rompe con los datos contextuales y los trasciende, y elimina las resonancias machadianas que recorrían algunas zonas de aquella publicación», ha escrito Miguel $\mathrm{Casado}^{27}$; c) la reescritura afecta, por supresión, a la extensión de los poemas, más breves en Pasión de la mirada; d) la supresión conlleva un singular proceso de abstracción por eliminación de los elementos referenciales, particularmente topónimos presentes en el título y en el interior de los poemas; e) el proceso de abstracción afecta al propio sujeto poético, que en los poemas reescritos aparece con un menor compromiso emocional que aquel de León de la mirada, libro concebido por el poeta como «el testimonio de un viejo y consumado amor» a una tierra; e) el proceso de reescritura no es, de todas formas, una simple supresión, sino que implica también sustituciones y readaptaciones.

Quisiera ahora añadir algunas puntualizaciones más que creo pertinentes. Los poemas reescritos llevaban entre paréntesis los siguientes títulos, numerados: XIII («Crepúsculo en Villamol»); XVI («Silencio en Golpejar»); XXV («Valdeón»); XXVIII («Vidrieras de la Catedral»); el XXIV no llevaba título, si bien la alusión a los Picos de Europa ubicaba el poema en un espacio concreto; en Pasión de la mirada desaparece numeración y título, y se corresponden del siguiente modo: el XIII con el que en Esta luz comienza: «La tarde entra de pronto en la cocina» ${ }^{28}$; el XVI con «Está tejida con azul la noche ${ }^{29}$; el XXIV con «Recuerdo que la tierra quiebra dura» ${ }^{30}$; el XXV con «En el más resistentes, más velado» ${ }^{31}$; y el XXVIII con «Un bosque inmóvil, sin espacio, pero» ${ }^{32}$.

\footnotetext{
${ }^{25}$ A. Gamoneda (2004), Reescritura.

${ }^{26}$ J. E. Martínez Fernández (2001), «Reescritura», La intertextualidad literaria, 161-166.

${ }^{27}$ M. Casado, «Introducción», Edad, op. cit, 27.

${ }^{28}$ A. Gamoneda, Esta luz, op. cit, 156.

${ }^{29}$ Ibid., 153.

${ }^{30}$ Ibid., 154.

${ }^{31}$ Ibid., 149-150.

32 Ibid., 166-167.
} 
La ausencia de título, así como la eliminación de la toponimia original, una vez reescritos, supone agregar los poemas a la corriente de lo abstracto, de lo simbólico, de la aparente a-referencialidad del resto de los poemas de Exentos II; los nuevos poemas quedan incursos en los espacios nuevos, ya no referenciales, sino imaginarios en el conjunto poemático de Pasión de la mirada. Los poemas pueden considerarse no mera recreación, sino poemas otros, por cuanto propician una nueva interpretación: un verso como «la geografía del final es blanca» ${ }^{33}$ puede aludir a la muerte, de acuerdo con el imaginario gamonediano; tal verso no está en el poema madre, («Valdeón»), pero sí el que posiblemente le dio origen, «volúmenes que tienden a la nieve», que no es más que una representación del paisaje de los Picos de Europa. El título referencial facilitaba el acceso interpretativo del poema; la ausencia del mismo propende a la oscuritas; la pregunta lógica es: con la reescritura, ¿no ha preferido el poeta ocultar el significado último del poema, provocar la imaginación lectora, desalentar la lectura realista y universalizar lo que nació agarrado a una realidad geográfica concreta? Acaso convenga añadir, de todas formas, que Antonio Gamoneda no ha desdeñado León de la mirada (1979) si tenemos cuenta el hecho de que fue reeditado en 1990, tres años después de la aparición de Edad en 1987.

El proceso de reescritura de los cinco poemas antedichos merecería un estudio aparte, pues en algunos casos tal proceso es complejo y nos permitiría asomarnos al laboratorio poético gamonediano. Aquí añado únicamente un par de notas más. La primera alude al hecho de que el poema «En el más resistente, más velado» ha sido nuevamente reescrito en el paso de Edad a Esta luz ${ }^{34}$. Disponía allí de 54 versos; en Esta luz, de 42, doce versos menos, con esa acusada tendencia del poeta a reescribir por supresión; sin examinar otros casos, cabe decir que de nuevo el poeta ha procedido a eliminar los topónimos que permanecían aún en el poema: obsérvese que entre los versos suprimidos están los siguientes: «prieto y oscuro de Corona; vete / despacio por el Pando»; «un único latido: el tormentoso / del Cares en su caz».

La segunda nota alude a algo no advertido por la crítica, según creo: el poema «En selva roja donde el agua nunca» ${ }^{35}$ recoge algunos versos del primitivo («Valdeón») suprimidos en el que rescribe aquel, «En el más resistente, más velado» ${ }^{36}$ :

Con sus alas revuelve la espesura
del interior y oscuridad desgarra,
y luego, lento, en el azul se eleva
y el canto le sostiene y pacifica. ${ }^{37}$

Un pájaro revuelve la espesura

$\mathrm{y}$, luego, lento, en el azul se eleva

y el canto le sostiene y pacifica $[\ldots]^{38}$

\footnotetext{
${ }^{33}$ Ibid., 149. nuestro estudio.

${ }^{35}$ A. Gamoneda, Esta luz, op. cit, 147.

36 Ibid., 149-150.

37 «Valdeón», León de la mirada (2. ${ }^{\text {a }}$ ed.) (1990), 48, vv. 5-8.

38 «En selva oscura donde el agua nunca», Esta luz, op. cit, 147, vv. 3-5.
}

34 También ha variado el poema final de Exentos II, «Dime qué ves en el armario horrible», que en el paso de Edad a Esta luz ha sufrido la mutilación de los cuatro versos finales, pasando de 10 versos a solo 6; pero no contemplamos este caso en 
112 Tropelías. Revista de Teoría de la Literatura y Literatura Comparada, 21 (2014) José Enrique Martínez

Como se ve, el taller de reescritura gamonediano es más complejo de lo que a primera vista pudiera parecer y carece todavía de un estudio iluminador.

\section{Referencias bibliográficas}

CASADO, Miguel, «Introducción», A. Gamoneda, Edad, Madrid, Cátedra, 1987.

GAmonedA, Antonio, León de la Mirada, 2. a ed., León, Diputación Provincial-Instituto Leonés de Cultura, col. Breviarios de la calle del Pez, 1990.

—_, «Poesía y conocimiento. ¿Qué conocimiento?», El cuerpo de los símbolos, Madrid, Huerga \& Fierro, 1997.

— Reescritura, Madrid, Abada Editores, 2004.

—, Esta luz, Barcelona, Galaxia Gutenberg-Círculo de Lectores, 2004.

MARTínez FERnÁNDEZ, José Enrique, «Reescritura», La intertextualidad literaria, Madrid, Cátedra, 2001, 161-166.

SOREL, Andrés, Iluminaciones, Sevilla, RD Editores, 2008. 